\title{
Trivial pursuits? Serious (video) games and the media representation of refugees
}

DOI:

10.1080/01436597.2017.1401923

\section{Document Version}

Accepted author manuscript

Link to publication record in Manchester Research Explorer

\section{Citation for published version (APA):}

Sou, G. (2017). Trivial pursuits? Serious (video) games and the media representation of refugees. Third World Quarterly, 39(3). https://doi.org/10.1080/01436597.2017.1401923

\section{Published in:}

Third World Quarterly

\section{Citing this paper}

Please note that where the full-text provided on Manchester Research Explorer is the Author Accepted Manuscript or Proof version this may differ from the final Published version. If citing, it is advised that you check and use the publisher's definitive version.

\section{General rights}

Copyright and moral rights for the publications made accessible in the Research Explorer are retained by the authors and/or other copyright owners and it is a condition of accessing publications that users recognise and abide by the legal requirements associated with these rights.

\section{Takedown policy}

If you believe that this document breaches copyright please refer to the University of Manchester's Takedown Procedures [http://man.ac.uk/04Y6Bo] or contact uml.scholarlycommunications@manchester.ac.uk providing relevant details, so we can investigate your claim.

\section{OPEN ACCESS}




\section{Third World Quarterly Routledge}

\section{Trivial pursuits? Serious (video) games and the media representation of refugees}

\begin{tabular}{|r|l|}
\hline Journal: & Third World Quarterly \\
\hline Manuscript ID & CTWQ-2017-0240.R1 \\
\hline Manuscript Type: & Research Paper (peer reviewed) \\
\hline Keywords: & $\begin{array}{l}\text { Human vulnerability, Media, migration and refugees, Representations, } \\
\text { Suffering others, Serious games }\end{array}$ \\
& $\begin{array}{l}\text { This article critically analyses the representational practices of serious } \\
\text { (video) games that focus on refugees. It argues that the technological form } \\
\text { of serious games can simulate the historical, political and socio-economic } \\
\text { factors that shape why refugees leave their home country, and their } \\
\text { experiences when travelling to host countries. Therefore they are able to } \\
\text { mobilise intellectual agendas, which challenge the de-contextualised } \\
\text { representations of refugees typical in traditional media. As such, they } \\
\text { challenge players to critically reflect on the complexities of refugee } \\
\text { experiences and politics, thereby presenting a potential to move away from } \\
\text { grand emotional discourses of pity and compassion. }\end{array}$ \\
\hline \multicolumn{2}{|l}{} \\
\hline
\end{tabular}

SCHOLARONE ${ }^{\text {M }}$

Manuscripts 
Trivial pursuits? Serious (video) games and the media representation of refugees

Gemma Sou ${ }^{1}$

Humanitarian and Conflict Response Institute, University of Manchester, Manchester, UK

\begin{abstract}
This article critically analyses the representational practices of serious (video) games that focus on refugees. It argues that the technological form of serious games can simulate the historical, political and socio-economic factors that shape why refugees leave their home country, and their experiences when travelling to host countries. Therefore, they are able to mobilise intellectual agendas, which challenge the de-contextualised representations of refugees typical in traditional media. As such, they challenge players to critically reflect on the complexities of refugee experiences and politics, thereby presenting a potential to move away from grand emotional discourses of pity and compassion.
\end{abstract}

\title{
KEYWORDS
}

Human vulnerability; media; migration and refugees; representations; suffering others; serious games

\section{Introduction}

Public representations of human vulnerability call on spectators - predominantly in the global north, to form 'a community of interest with the oppressed and the exploited', according to Arendt's definition of solidarity ${ }^{1}$. Critical debates centre on how these public images conjure up ideas of distant others and of humanity at particular times and in particular places. ${ }^{2}$ This can have 'real world' consequences on the responses, attitudes, and behaviours of western spectators, including levels of charitable donations, support for NGOs, public policy, activism, and the formation of a global civil society, or a cosmopolitan public. $^{3}$ Therefore, this work needs to be part of the mainstream of development research, rather than marginalized as peripheral to the 'real work' of development4.

However, studies highlight how visual representations of human vulnerability, and refugees in particular, often rely on decontextualized, apolitical and simplified narratives about why people leave their home countries and possible solutions. ${ }^{5}$ Common tropes are the orientalizing and dehumanizing portrayals of refugees as victims, which rely on grand emotional discourses that evoke sentimentalities of pity and compassion for suffering others. ${ }^{6}$ This can entrench problematic hierarchies between the global north and south, and can catalyse short-lived responses such as donations to refugee charities, which does not address the economic and socio-political factors that cause people to flee their home countries. ${ }^{7}$

${ }^{1}$ CONTACT Gemma Sou Email gemma.sou@manchester.ac.uk Twitter: @gemmasou 
Discussion of the representation of human vulnerability, has been grounded in analysis of images. This article seeks to expand this debate by exploring how the technological form of different media shapes the representational practices of suffering distant others, and the potential effects this may have on spectators. In particular, this paper explores serious video games that focus on refugees. Serious video games are distinct from mainstream commercial video games that are principally designed for entertainment. Although the definition of serious games is a contested one, they are widely defined as games designed to facilitate sustained learning, knowledge acquisition and to encourage activism. ${ }^{8}$ Serious games that focus on refugee issues have been launched by a diversity of organisations from international development organisations such as the United Nations Higher Comission for Refugees (UNHCR), international non-governmental organisations (iNGOs), grassroots activist groups, news media outlets and private companies.

This article begins with a critical review of the public representations of human vulnerability, focusing in particular on the decontextualized narratives that tend to be created, and the problematic affects these representations can have on spectators. The article then draws on serious games literature to lay out a theoretical approach for analyzing the representational practices of video games. This draws on Bogost's work on procedurality and procedural representation ${ }^{9}$. Following this, the paper applies this theoretical framework to analyse the representational practices of three refugee serious games: Frontiers: Welcome to fortress Europe ${ }^{10}$; Cloud chasers: Journey of hope ${ }^{11}$; and Against all odds. ${ }^{12}$

The article makes two interrelated arguments. First, that the technological form of video games allows them to construct sophisticated messages about the political, social, economic and historical factors that shape refugee processes that are often marginalized in public representations. In this way, they challenge the decontextualised narratives that tend to dominate in other media such as fundraising campaigns, social media, film, photography, and news. Second, that video games have distinctive rhetorical power because their technological form allows them to retain highly complex narratives, but also remain highly learnable and understandable for users who may not be familiar with refugee issues.

Although this article focuses on video games in particular, it is revelatory because it demonstrates that technological form can significantly shape the representations of human vulnerability, and in ways that have potential to address key critiques of public representations of refugees. As such, this paper sets out to illuminate the limitations of public representations of refugees and point to serious games as a potential avenue to address some of these concerns. The paper also demonstrates a need for scholars working on the visual politics of human vulnerability, to engage more critically with the technological form of different media, and how this shapes representational practices. This is an increasingly important and inescapable area of concern for such scholars given the increasing use of alternative 
technologies such as video games and virtual reality by organisations working on or interested in refugee issues ${ }^{13}$.

\section{Media representations of refugees: simplification and grand emotional discourses}

Critical discussions about the media representations of human vulnerability, including refugees, has centred on analyses of the visual and textual representations constructed in TV, film, social media, the news, and NGOs' fundraising and advocacy campaigns. ${ }^{14}$ These conversations highlight the tendency to rely on aesthetics of suffering, which can decontextualise and simplify why people flee their native homes and how this can be addressed. There is a tendency to rely on highly emotive imagery that depicts refugees at their most personal and vulnerable moments in order to depict a sense of tragedy and the raw 'reality' of human suffering. ${ }^{15} \mathrm{~A}$ common trope is to focus on children, women, the elderly and those who are injured or sick, which convey ideas of helplessness, as they tend to be internationally recognised as 'symbols of distress'. ${ }^{16}$ This is because they are deemed to be passive and having less agency, and are therefore 'more deserving' of our sympathy and support. ${ }^{17}$ A notable and infamous illustration of this approach was that the photo taken of the dead body of Aylan Kurdi, a small Syrian boy who washed ashore in Turkey. ${ }^{18}$

There is also a reliance on images of large groups of people. A report on the media representations of migratory movement states

"There is a tendency, both among many politicians and in sections of the mainstream media, to lump migrants together and present them as a seemingly endless tide of people who will steal jobs, become a burden on the state and ultimately threaten the native way of life." 19

This inevitably portrays refugees as lacking any individualising features, because people are aggregated into large abstract groups e.g. refugees. This ultimately homogenises refugees, and denies them their personal experiences, voice and identity. ${ }^{20}$

Public representations tend to strip refugee issues of their context as they mobilise apolitical and ahistorical explanations about why people leave their countries, and the constraints and challenges they face during journeys, and when they arrive to new countries. ${ }^{21}$ Refugees are simply seen to exist as there is marginal engagement with the broader structural factors that insidiously and gradually force people to flee their homes. This naturalisation of refugees again constructs vulnerable people as 'ideal', victims of a situation that is beyond their control. ${ }^{22}$ Simplification is not entirely surprising as the processes that shape refugee issues are complex and would require communication of broader processes including capital accumulation, dispossession, exploitation, oppression, commoditisation, privatisation, liberalisation, market-led agrarian reform, debt crisis, or structural adjustment programmes. ${ }^{23}$ That is, topics which are difficult to distil and convey in an engaging and legible way via 
media texts which may be limited to a single image, a two-minute fundraising campaign, a 140 character tweet, a ninety minute feature film, or a five hundred word newspaper article for example.

This lack of engagement with the complex interplay of social, political and economic factors that shape refugee experiences and issues, means that the causes and solutions to so-called 'refugee crises' become severely filtered into simplistic narratives that are sanitised of sufficient complexity. Additionally, in suppressing the political, historical and socio-economic factors that shape refugee issues, media representations lack a level of reflexivity about the limits of interventionist projects to promote sustainable social change.

Additionally, media representation are often much more to do with the western audience, than the actual lived experience and accuracy of these representations. ${ }^{24}$ Rather than invoking feelings of solidarity with distant suffering others, which can incite long-term acts towards social change, they invoke grand emotional discourses of guilt and indignation, or empathy and gratitude. ${ }^{25}$ This emotionoriented process is associated with short-term participation in develop issues by western spectators, typically through donations to charities. However, donation to charities does not address the structural relations that so heavily influence the causes and solutions to refugees. ${ }^{26}$ Furthermore, it ultimately constructs a reductive binary and palliative care relation between supposed western saviours and helpless others, which reinforces the unequal power relations reminiscent of the colonial legacy. ${ }^{27}$

Against this background this article now introduces serious games. This is followed by a review of their technological form and how it shapes their representational practices.

\section{Serious games}

Abt coined the term 'serious game' when discussing card and board games ${ }^{28}$. Despite the introduction of technological and computer devices his definition is still relevant. He argues that serious games have an explicit and carefully thought-out educational purpose and are not intended to be played primarily for amusement. ${ }^{29}$ Digital serious games can be played on video game consoles, computer tablets; however, many are mostly freely available to play online. The target age groups of serious games are preschool; elementary school; high school; college, adult and senior. These games also have a diverse player audience, which includes those who rarely play any kind of game, and those who dislike or even avoid playing video games. ${ }^{30}$ Serious games have received considerable academic attention within pedagogical and psychological studies, and the most frequently occurring outcomes are knowledge acquisition, content understanding and affective and motivational outcomes. ${ }^{31}$

A problem with the term 'serious game' is that there appears to be a contradiction as the terms 'serious' and 'game' may seem to be mutually exclusive. However, serious games do not try to distinguish themselves entirely from entertainment as there is not a binary between seriousness and entertaining - 
it is acknowledged that entertainment can tackle complex issues and titillate audiences. ${ }^{32}$ Regarding the term 'game', there are difficulties in defining what constitutes a game. A useful definition is that of Michael and Chen who describe games as: '...a voluntary activity, obviously separate from real life, creating an imaginary world that may or may not have any relation to real life and that absorbs the player's full attention. Games are played out within a specific time and place, and are played according to established rules'. ${ }^{33}$

Serious games allow learners to explore situations that are impossible to experience in the 'real world' for reasons of safety, cost, time, etc. Ratan and Ritterfeld categorise the driving force that makes a game serious and not simply entertainment into five areas: academic education, occupation, health, military, marketing, and social change. ${ }^{34}$ This article focuses on games for social change, and there are now dedicated institutes and international movements such as the Serious Games Institute ${ }^{35}$; Games for Change ${ }^{36}$; and Persuasive Games ${ }^{37}$ that specialise in creating digital games for social change. The current study explores the representational practices of serious games that focus on refugees. These games tend to aim to educate users about the complexity and challenges of refugee experiences, journeys and politics. Players can learn about these particular issues when playing the game according to the games' rules of engagement. Examples of serious refugee games include: Papers, Please ${ }^{38}$; Against all Odds ${ }^{39}$; My Life as a Refugee ${ }^{40}$; The Migrant Trail41; Darfur is Dying ${ }^{42}$; Cloud Chasers: Journey of Hope ${ }^{43}$; North ${ }^{44 ;}$ Zaytoun ${ }^{45}$; On the Ground Reporter: Darfur46; Food Force ${ }^{47}$; and Frontiers: Welcome to fortress Europe. ${ }^{48}$

\section{Possibility spaces, procedural representations and procedural rhetoric}

Representations within video games are not solely constructed through words and images, but also through their simulation of processes; a process known as procedurality. ${ }^{49}$ Procedurality refers to the way that social processes and systems are designed and constructed in video games so that players can explore them. Bogost argues that when video games represent things, whether earth invading aliens, or a border crossing, they do so by designing and establishing computational models of these topics that are governed by particular rules of play and engagement. ${ }^{50}$ These models are smaller abstracted versions of a complex system that explain the logic of how something works or should work. In video games, these models are oriented towards human experience and players then take on roles that are designed to simulate some type of experience and which makes us play a role in accordance with some logic. ${ }^{51}$

Procedural representation differs to textual or visual representation because processes are used to represent 'real world' processes that players are able to explore through play. This form of representation cannot be captured in media such as TV, poster campaigns and literature that only visualise and describe processes. Therefore, procedural representation can only be encoded into media 
that allow the execution of processes, such as videogames and virtual reality. As such, procedural representation is the result of conscious decisions made by programmers when deciding on the rules rather than the images and letters of the game. ${ }^{52}$ If video games are understood in this way, it is possible to begin decoding and deliberating the purposive arguments that they create.

Procedural representations are located within video games' 'possibility space'. The possibility space is a term that is used to understand games, whether video games, board games or the games that children play in a playground. It denotes all of the space that a player can navigate when playing the game. Through the gamification of social issues, gamers explore these topics when they navigate the possibility spaces of video games through play. ${ }^{53}$ Exploration of this space is permitted by all of the movements and actions that a player can take and which are permitted by the rules of the game. Typically, a game provides players with a limited number of possible actions and its game play consists of their iteration. For the real-time strategy genre, these possible actions tend to include gathering resources, building, and commanding units, whereas typical procedural forms for first-person shooters are movement, shooting, and taking cover. Within these possibility spaces the player can explore multiple narratives and pathways in relation to a particular issue, as there is no one set narrative or pathway that a player must take ${ }^{2}$. Instead the narrative that a player explores is dependent on choices and actions taken by the player. This differs to TV, film and novels, which tend to adopt linear storytelling, whereby the audience can only imagine the possibility spaces that take place outside of the dominant narrative.

Video games also have procedural rhetoric, which refers to the ways that the representation (or simulation) of social processes make persuasive arguments. Just as verbal rhetoric is the practice of using oratory persuasively and visual rhetoric is the practice of using images persuasively, procedural rhetoric is a general name for the practice of authoring arguments through the modeling of processes..$^{54}$ This is achieved not only by persuasive narrative and graphics, but also on the level of game play, by shaping and limiting a player's interaction with the simulated reality through computation and execution of processes. Playing a video game with procedural rhetoric requires exploring the possibilities that are authored in the rules of the game, not necessarily because these processes represent 'reality', but because they make arguments about how a process, such as healthcare, migration or aid distribution works or should work for example. ${ }^{55}$ This allows people to understand how social systems, institutions and issues function. Procedural rhetoric seeks to alter behaviours and opinions; however, it avoids teleological persuasion as it relies on communicating ideas in innovative and expressive ways when demonstrating how a particular system works in the 'real' world. Therefore, procedural arguments

\footnotetext{
2 Procedural rhetorics are not dependent on computations because they can be simulated in non-computational mediums such as boards games or role-playing for example. However, procedural mediums (i.e. virtual reality and video games) that allow authors to simulate processes (procedurality) computationally are particularly suitable.
} 
require their players to critically disassemble them and come to their own conclusions. In this way, they are persuasive rather than being discursive in the Foucaldian sense of constituting part of an apparatus that supports ideas that must be internalised by a person. ${ }^{56}$

\section{Serious games about refugees}

This section introduces the three case serious games of this research. Against All Odds was developed by UNHCR, Frontiers by a non-profit arts group, and Cloud Chasers was a commercial for-profit venture by a private company. The games were played critically, and the researcher applied an extensive textual analysis to unpack the hidden messages and rhetorics that are proceduralised in the games. Their similarities in game player format and content make them useful cases for this research. To understand how serious games represent refugees, games which focus most closely on refugee experiences were chosen. For example, all three are role-playing video games that focus on the journey of refugees across borders - both fantastical and 'real life' borders. Whereas games such as 'Papers Please', 'Food Force' and 'On the Ground Reporter' focus on border control officers, humanitarian aid workers, and journalists respectively.

The three games are also made up of multiple and discrete stages where the player carries out different tasks. Playing the different tasks allows the research to critically unpack the distinct and different procedural rhetorics that are embedded into each of the mini tasks, which provides a large set of data to analyse. This game format is not present in other games such as 'Migrant trail' and 'Darfur is Dying' or 'On the Ground Reporter'. Finally, all three are interesting because they give emphasis to the personal identities and experiences of refugees, which allows the research to illustrate how serious refugee games challenge and speak back to mainstream media narratives of refugees. In contrast, games such as 'Food Force', the 'Migrant Trail' and 'Darfur is Dying' do not do this. . As such, all three games are revelatory because they mobilise procedural representations and procedural rhetoric about refugee issues within their possibility spaces. Furthermore, they demonstrate how the technological form of video games allows them to embrace and communicate the complexity behind refugee experiences, politics, and identity.

Against All Odds is freely available online, and was played on a desktop. Whereas Cloud Chasers was downloaded on the Apple App store for $£ 3.99$, and was played on an Ipad. Finally, in order to run Frontiers on a desktop, it was necessary to download and set up a Steam account, and to download and pay for the Half-Life 2 application. Frontiers is an online multiplayer game; however, in order to play with other people a local area network (LAN) party had to be set up. In particular, the researcher invited five other people with game compatible consoles, to establish a LAN connection between the devices using a shared router. The researcher played Against All Odds and Cloud Chasers for approximately 
45-60 minutes, thirty times. However, because the researcher was reliant on other people to play Frontiers, it was only possible to play this game seven times. However, each play lasted for two to three hours. Multiple plays allowed the researcher to make different choices each time the game was played. This ensured data was gathered about how different player choices shape the outcome of the game, and it allowed the researcher to explore the multiple narratives and routes proceduralised in the games. I completed all stages and mini games in Against All Odds; however, to investigate Cloud Chasers and Frontiers, completing two stages, which include several mini tasks allowed sufficient engagement with the game in order to unpack their different procedural rhetorics. To supplement playing the game, the researcher also watched gameplay walk through and game commentary videos of Against All Odds ${ }^{5758}$, Frontiers ${ }^{59}$ and Cloud Chasers on YouTube ${ }^{60}$.

Before beginning discussion of the three case games, it is important to bear in mind that there are serious refugee games that do not create a procedural rhetoric and which continue to decontextualise refugee issues. A notable example is Darfur is Dying, which was launched in 2006 by the Music Television University. ${ }^{61}$ Players control a Darfurian refugee who must forage for water in the desert and try to avoid being captured by the militia group, Janjaweed. However, the Darfurian character is inevitably captured and placed in a refugee camp, where the player must ensure their character eats and receives first aid for example. The game makes a political statement by proceduralising the challenging experiences of Darfurians. The game raises awareness about the situation in Darfur, but it fails to construct a procedural rhetoric about the political and historical events that created the conflict and why conflict resolution is so challenging as a result. Therefore, Bogost suggests Darfur is Dying oversimplifies an incredibly complex conflict, which is typical of the decontextualized narratives in traditional media62.

\section{Cloud Chasers: A Journey of Hope}

The Switzerland-based game studio, Blindflug design games that 'center around complex, real world dilemmas', and 'believe, that games are an incredible medium of letting players experience the most complex of problems as they are playing', ${ }^{63}$ In 2015 they released a mobile game, Cloud Chasers: $A$ Journey of Hope, which was inspired by the so-called Mediterranean refugee crisis 2015/2016. Cloud Chasers tells the story of a father who is a corn farmer (Francisco) and his daughter (Amelia) who must survive in a world where Earth is almost completely dry. In hopes of a brighter future they begin a journey to Spire, a city that promises refuge and life, and where only the privileged are allowed to live. As the player, you must navigate Amelia and Francisco through five stages, which are five different deserts full of dangers. After each stage, you enter a different city where the characters can take rest bite and visit the town shop and the healer before setting on to the next desert. All along, players must monitor the characters' water, and use their glider to fly and harvest water from the remaining clouds in

URL: https://mc.manuscriptcentral.com/ctwq E-mail: twq.admin@tandf.co.uk 
the sky, a task that is not easy mainly because of the special machines called Cloud Harvesters that are sent to collect water and will attack Amelia and Francisco.

Although Cloud Chasers is set in a fantastical world, encoded into the game are several procedural rhetorics. The first of these focuses on the difficult choices and circumstances that refugees typically face en route to host countries. Francisco and Amelia's story is centered on choices, some of which are more innocuous than others. Depending on what you choose, the outcome will be different. Throughout the game, the two protagonists come across various hidden items, such as medication, empty houses, abandoned trucks, and other people seeking refuge. You must decide whether you will help other refugees, and which items are worth taking with and which to leave behind. This element of the game play forces the player to consider the consequences of one's actions by embedding ethical messages in its proceduralisation of refugee experiences. For instance, in stage three you encounter two refugees who are in need of water, and you must decide whether to spare the little water you have, or to keep it for yourself. If you decide to share your water this increases the likelihood that the characters will die from dehydration, later in the game. Therefore, the decisions that the player takes also affect the characters' health, hunger as well as their mood levels - all elements that the player must maintain throughout the game, and which are indicated to the player through the dialogue between Amelia and Francisco. -. As such, Cloud Chasers is interesting as it proceduralises and constructs a procedural rhetoric about the vulnerabilities, emotional states, including anxieties and sadness of refugees.

Cloud Chasers also centres on proceduralising the personal histories, and personalities of the two characters. This is explored through encounters with other refugees, the protagonists' diary entries, and the interaction between Francisco and Amelia, which includes the bedtime stories Francisco tells. This is interesting as it challenges mainstream media representations of refugees that focus on 'mass movements' of people, which obscure the identities, voice and individuality of refugees. Through these rhetorical processes Cloud Chasers aims to persuade players to read the experiences of refugees in a way and from an angle that is often silenced in public representations. That is, it confronts players with the very personal challenges and emotional state of refugees.

\section{Frontiers: welcome to fortress Europe}

Frontiers is an online game that was produced by Austrian artist group 'Gold extra' in 2015. It is a multiplayer game for up to 16 players, where one party is made up of refugees that are predominantly unarmed, and who are trying to either cross a specific area (typically a border) or escape a raid situation. The other party, which mainly consists of security and military personnel, may use all necessary force to prevent the passage of these migrants. As a player, you must decide whether to play as a refugee or border control personnel. As a refugee, you must travel from Sub Saharan Africa to London. As a member of the border control forces, you must try to stop the movements of refugees by 
arresting them and sending them back to their home country, or you can choose to shoot a refugee and kill them.

All players are presented with information about the political and socio-economic situation in the countries that refugees are leaving, as well as the personal histories of individual refugees. This is presented through static images of refugees that are accompanied with biographies. 'Players controlling migrants face up to four border situations on their route: when leaving North Africa; entering Europe via the Spanish port city Ceuta; departing Rotterdam where the player must ensure the migrant enters a container ship to London, where the refugee may face border control for a final time. Players of refugees will be challenged by a variety of obstacles and scenarios that proceduralise the struggles that refugees are forced to deal with every day en route to host countries. As with Cloud Chasers, players must maintain refugees' wellbeing, health and safety by making decisions such as where and when they will sleep, and what they will eat. The game also proceduralises feelings such as sadness when loved ones, and fellow refugee players die. Through timed mini tasks, where refugees must try to avoid and escape from border control officers, the game creates a procedural rhetoric of the desperation, stress and urgency that refugees face.

For those playing as border control officers, you are regularly confronted with the personal narratives of migrants, which you are asked to consider when deciding whether to let the person escape, arrest them, or shoot them. As such, Frontiers produces a persuasive procedural rhetoric that immigration laws are not universally correct across time and space, and that individuals may be forced to choose between their personal moral codes and governmental regulations of immigration. Additionally, for each refugee that is killed, a white dove - symbolizing the human rights index - will gradually turn from white to red in the left-hand corner. Interestingly, if you decide to shoot a refugee, all players controlling border control officers will have points deducted, and the particular player will have to undergo extra training. Through this, Frontiers is able to create a procedural rhetoric about collective forms of responsibility as well as the accountability that individual border control officers have to one another.

\section{Against All Odds}

Against All Odds was developed in 2007 by UNHCR, and it has been released in ten languages. The UNHCR decided to develop a web-based serious game in order to reach a large number of young people, which would require no distribution costs and minimal marketing costs. The game works to teach players 'the importance of treating refugees with tolerance and respect' by 'letting you experience what it is like to be a refugee'. ${ }^{4}$ The player takes the role of a refugee, which may be an adult man or woman. The player must choose a name, and then is presented with three stages ('War and Conflict' 'Border Country', and 'A New Life') that are each broken down into four mini games that the player navigates through. The game begins in the refugee's home country, and then proceduralises the 
refugee's exit from their home country, following them along their journey through border countries to a foreign society, where they then struggle to integrate into society.

The mini games in Against All Odds have several procedural rhetorics about different refugee experiences. For instance, mini game four in 'War and Conflict' focuses on the escape routes that refugees take when exiting their home countries. Players cannot fly out of the country because the refugee lacks financial resources, nor are they able to take a boat as it is full. Inevitably the player must choose to exit on the back of a truck, but the truck is full and so they must decide whether to leave behind their family, friends or neighbours. Following this, the player is told that the driver's price is too high and you are given the option to barter. Despite this, it soon becomes clear that the refugee has little leverage and so you must decide whether to pay the asking price or choose another route. As such, this mini game mobilises procedural rhetoric about the difficult decisions and dilemmas that refugees must confront when exiting their country, as well as their constrained financial resources, which limit their power and flexibility when travelling.

Other procedural rhetorics focus on refugee experiences in places that are foreign to them. For example, in mini game two, in the 'Border Country' stage, the refugee avatar arrives at a refugee reception center where the player is up against a two-minute timer to find an interpreter who will help them with language difficulties. There are clues to find the interpreter; however, they are spoken or written down in a language that you do not understand. Then in mini game four of 'Border Country', the refugee avatar starts school in a new country. The teacher and classmates talk to you, but in another language that you do not understand. As the player, you are given options of how to respond and you must guess which to choose. Inevitably, some of the answers the player chooses are inappropriate answers to questions, and which expose the refugee's lack of understanding to the rest of the class. These mini games create procedural rhetorics about the cultural difficulties of arriving to a new country. In particular, the confusions, frustrations and barriers that are created when a refugee does not speak the local language. Mini game one in 'Border Country' is also notable. Players control the refugee character to find shelter for the night in an unfamiliar border town. Whilst searching, the refugee encounters xenophobic comments and hostility from locals who are unwilling and/or afraid to help the refugee. In this way, the game creates a procedural rhetoric about the stigmatisation and marginalization that refugees can encounter when arriving to foreign countries.

\section{Playful contextualisation of refugees: critical reflection on intellectual agendas}

All three case games place the player in the first-person position, and construct a persuasive procedural rhetoric about the complicated scenarios, challenges and decisions that refugees face. The aim of this is to force the user to experience the perspective of a refugee, and to face dilemmas, and observe what 
can happen when certain decisions are made. However, procedural representations remain representations and they do not attempt to perfectly simulate 'real' experience of suffering others. However, as Belman and Flanagan argue, '[g]ames are frameworks that designers can use to model the complexity of the problems that face the world and to make them easier for the players to comprehend'.65 That is, the technological form of video games is able to embrace the complexity of refugee issues. For instance, the case games demonstrate the ability of serious games to proceduralise and persuade players about the personal identities, voice, and histories of suffering others. This signifies a shift away from the homogenistion of suffering others into abstract groups of voiceless, faceless, and nameless peoples. ${ }^{6}$ Silverstone argues that this personalization of suffering people foregrounds vulnerable people's agency and dignity, which reduces the distance between spectator and suffering others. ${ }^{67}$ However, serious games are able to avoid exaggerating suffering others' agency to influence refugee politics and experiences, which can redistribute responsibility onto vulnerable others. This is because the structural constraints on refugee behaviours and choices can be foregrounded and proceduralised in the rules of the game.

The case games also demonstrate how serious games can expose users to new experiences that can help them to gain information about the causes and solutions to refugees. These complex narratives are facilitated by their large possibility spaces, which allow them to challenge players' perceptions and understanding of refugees by constructing a persuasive procedural rhetoric about the personal challenges and constraints that they face when leaving their home countries. In particular, the games represent refugees' movements and experiences as a complex process fraught with political, socioeconomic, ethical, practical, personal and logistical challenges. In this way, the case games signify a shift away from victim oriented and orientalizing portrayals of suffering others in the global south. Of course, this is not true of all serious games that address refugees, and the discussion of Darfur is Dying demonstrated this. However, it is critical to recognise that serious games' large possibility spaces afford game designers the opportunity to represent refugee issues in more sophisticated ways that can make claims about the particular interrelations between social processes, the causes and solutions of refugee processes, the limits of interventionist projects to address refugees, and/or how society might benefit by changing the rules. ${ }^{68}$ Therefore the technological form of video games provides potential to challenge simplistic and hegemonic narratives about refugees.

Cinematic representation also often embraces complexity and can help chart a chronology about refugee experiences and highlight its contextual constraints. ${ }^{69}$ However, films tend to adopt linear storytelling, whereas players of the three case games are able to navigate multiple stories/pathways and encounter more holistic contextualization of refugee processes and experiences. As such serious games can make visible the stories that are often marginalised or completely obscured in other popular culture media. For example, and as discussed above, the games do not suggest that the solution to 
refugees is simply a matter of more aid money - an argument mounted by many fundraising campaigns. But instead they construct a procedural rhetoric that addressing the causes and solutions to refugees is a protracted and complicated process that involves multiple actors.

Therefore serious refugee games are not solely dependent on visceral imagery and the invocation of emotional discourses of guilt, pity and sentimentality in order to establish emotional connectivity and proximity between spectator and sufferer - tactics that are often used in other popular culture representations of refugees. ${ }^{70}$ In this way serious games can challenge players to use their agency to critically reflect on the intricacies and challenges of refugee issues, and to make choices that must be considered in light of a mosaic of factors when navigating different 'levels', scenarios and tasks. ${ }^{71}$ The shift towards outwards reflection on refugee processes can be understood as a form of reflexive particularism, whereby there is deliberative cognitive reflection that asks players to rely on their individual judgement as they decide for themselves what the problem is, what the solution is and what their personal role is in the 'real world'. The fact that, unlike other media, computer games give players the sense that they are 'co-creators' of the game, which makes serious games a forceful discursive space and practice, with real enough power to influence the terms in which people think and feel. ${ }^{72}$ This reflects serious refugee games reliance on persuasion rather than didacticism. This is significant because it is important for western audiences to be engaged in a long conversation about the complexity surrounding refugee experiences if they are to avoid misrecognition of the root causes, and if an ethical discourse on public action is to be mobilised $^{73}$.

Critical engagement with the causes and solutions to refugees is also important because there is evidence that western audiences have become increasingly literate, and cynical of media representations of suffering others that focus almost exclusively on human misery, agony and/or death. For instance, Hutchison et al. and Tallon and McGregor argue that many popular representations of human vulnerability and suffering continue to maintain a status quo that assumes three key ideas about western audiences. ${ }^{74}$ First, that they insufficiently understand refugee issues; second, that they do not wish to engage with the complexities of refugee processes; and third, that they are only receptive to representations that evoke intense emotions such as fear, pity, guilt and hope. As such, media representations can patronise audiences and maintain the reproduction of simplistic and emotive images, texts and narratives about distant others.

However, serious refugee games have the potential to address this problem, because their technological form allows them to confront players as individuals who want to engage with the complexity of refugee issues. The intellectual agendas that are mobilized by serious refugee games challenge western audiences to reflect critically on the myriad of factors and challenges related to refugee processes. By creating a simulated environment, the player can potentially step away and think 
critically about those problems. ${ }^{75}$ In foregrounding complex procedural representations of refugee issues as well as the personal identities and histories of suffering others, audiences are asked to recognize the complex stories of social injustice, by showing that suffering others act within - and are constrained by - broader structures that produce global injustices. ${ }^{76}$ This is not to say that serious refugee games avoid generating empathy and other emotional responses to suffering others. Rather, this research argues that the procedural rhetorics in serious refugee games do attempt to influence the emotions of players, but that this is attempted through discourses of social injustice. In this way, their focus on social injustices is progressive in the field of media representations of suffering others because they are not solely dependent on apolitical and sentimentalist and grand emotion-oriented discourses of suffering and indignation, which are associated with audiences' short-term responses such as charity donations. ${ }^{77}$ This is noteworthy because previous research states that discourses based on social injustices have potential to invoke feelings of solidarity and galvanise more long-term engagement with the politics of suffering others ${ }^{78}$ Nevertheless, the actual impacts on player audiences are still unknown, and are an important line of inquiry for future research.

However, if an individual is presented with complexity, then one must ask whether this renders serious games too difficult and frustrating for people unfamiliar with refugee issues. This is where serious games are particularly valuable because they are able to communicate complex ideas in an accessible way to audiences..$^{79}$ Pedagogical and psychological studies have shown that knowledge acquisition and content understanding are among the most frequently occurring outcomes of playing serious games and there are three principle reasons for this. ${ }^{80}$ First, serious games are able to create immersive worlds that intrigue and engage players. This draws players into very challenging learning experiences and motivates them to continue, often for long periods of time. Second, problems in serious games can be well ordered. In particular, early problems and scenarios are designed to lead players to form good guesses about how to proceed when they face harder problems and more complex ideas later on in the game. This ensures players are not overwhelmed with too much information at once. Third, serious games are often designed to be within players' 'regime of competence'. That is, challenges are difficult and complex, but they are pleasantly frustrating because players receive feedback on their progress. This process makes players feel that their efforts are paying off and encourages them to continue playing. ${ }^{81}$ In sum, serious games make complex ideas highly learnable, and they motivate people to continue playing.

\section{Conclusion}

Within the literature on representations of human vulnerability and refugees in particular, focus has typically been on visual and verbal representations that are encoded into imagery and oratory. This article adds to this literature by introducing serious games. It shows that the technological form of serious games allows them to mobilise sophisticated and intellectual agendas that proceduralise the 
political, economic, social, cultural and historical processes surrounding refugees. If done carefully, this simulation gives serious games a procedural rhetoric about refugee processes, including the causes, solutions and constraints to refugee experiences and politics. As such, serious refugee games may be viewed as a response to current problems with the ways that refugees are represented in traditional media.

Furthermore, serious games are able to communicate multilinear storylines, which allows players to encounter multiple and alternative narratives about refugees that are often foreclosed in the linear storytelling modes typical of traditional media. Reflection on sophisticated and complex accounts of suffering distant others allows western audiences to critically explore complex dimensions of refugee issues and to recognise the social injustices which cause people to leave their home countries, and their experiences en route and when arriving to host countries. With this in mind, serious games present potential to move away from emotionally charged social relationships between spectators and sufferers, and towards the prospect of galvanizing western audiences to engage in 'alchemical' long-term public action concerning refugees ${ }^{82}$. Of course, the current study is unable to draw any conclusions on this, and so I suggest a need for further research into the particular effects that serious refugee games have on end-users.

Further to this, pedagogical and psychological studies show that the video game form has significant impact on players' knowledge acquisition, content understanding and affective and motivational outcomes..$^{83}$ This is not only because games are engaging, but also because they are uniquely able to present complicated ideas in a more accessible and understandable way because of the ways that people learn through play, regardless of their previous knowledge of the particular topic at hand. Therefore, it is important that western audiences develop the ability to understand and critically unpack their messages - to dissect what they are arguing, both explicitly and implicitly. With this, players can consent to, contest or discard them in their day-to-day lives. A literacy of procedural representations is particularly crucial because video games are a uniquely persuasive medium, and because western society is increasingly embracing procedural media such as video games and virtual reality within the development industry. ${ }^{84}$

Lastly, serious refugee games present scholars of media representations of human vulnerability with a petri dish of questions yet to be explored. Most notably, there is a need for further empirical research on the representations within current serious games. Do their messages differ depending on the organisations that are creating them? How and why? Relatedly, the three case games are produced by an international organization, and a not for profit activist group and a commercial for profit company. This raises questions around the likely market and outreach impacts of the games, as well as ideas around the commodification of solidarity with refugees, which speaks to Chouliaraki's work on post- 
humanitarianism ${ }^{85}$. Certainly, the question of who is playing these games and the affects they are having on users is of central importance, and further research here can answer questions around the actual potential of refugee serious games to encourage user engagement with the politics of refugees, rather than short-term engagement in the form of charity donations for instance. Other questions concern who is behind the scenes working to create storyboards and construct computational models of human vulnerability and related experiences and processes? This inevitably raises a question about the inclusion of vulnerable others when creating these games. The problem of bringing in the voice of suffering others is a constant challenge within the representations literature; however, it is a necessary step in the process towards more ethical representations and to overcome the paternalistic north-south relationships that often arise if portrayals of the global south are left in the hands of those residing in the global north.

\section{Acknowledgements}

I am very thankful for the comments, suggestions, and German language support that Birte Vogel gave to me when I was working on this paper. I would also like to thank the two anonymous reviewers, for their interesting and insightful comments, which have made this a much stronger paper.

\section{Note on Contributor}

Gemma Sou is a Lecturer at the Humanitarian and Conflict Response Institute (HCRI) at the University of Manchester. Her research is interdisciplinary and explores the experience of 'at risk' and marginalised groups in cities of the Global South, as well as media representations of disasters and suffering others. She is particularly interested in using postcolonial theory to challenge and reinterpret dominant discourses about disaster preparation, response, and recovery. She completed her $\mathrm{PhD}$ in the Global Development Institute (formerly the Institute for Development Policy and Management) at the University of Manchester, UK.

\section{Bibliography}

Abt, C. C. (1970). Serious games: The art and science of games that simulate life. New Yorks Viking: 6. Against all odds. (2007), http://www.playagainstallodds.ca Accessed April 28, 2017.

Arendt, H. (1973). The origins of totalitarianism (Vol. 244). Houghton Mifflin Harcourt.

Belman, J., \& Flanagan, M. (2010). Designing games to foster empathy. International Journal of Cognitive Technology, 15(1), 11.

Bogost, I. (2008). The rhetoric of video games. The ecology of games: Connecting youth, games, and learning: 117-140.

Bogost, I. (2010). Persuasive Games: The Persuasive Power of Video Games. Cambridge: The MIT Press.

Boltanski, L. (1999). Distant suffering: Morality, media and politics. Cambridge: Cambridge University Press.

Chouliaraki, L. (2006). The spectatorship of suffering. London: SAGE.

Chouliaraki, L. (2013). The ironic spectator: Solidarity in the age of post-humanitarianism. London: John \& Sons. 
Cloud chasers: Journey of hope. (2015), http://cloudchasersgame.com Accessed May 21, 2017.

Connolly, T. M., Boyle, E.A., MacArthur, E., Hainey, T., and Boyle, J.M. (2012). A systematic literature review of empirical evidence on computer games and serious games. Computers \& Education, 59(2): 661-686.

Darfur is Dying (2006). http://www.gamesforchange.org/play/darfur-is-dying/ Accessed June 3, 2017.

Dogra, N. (2012). Representations of global poverty: Aid, development and international NGOs. London: IB Tauris.

Frasca, G. (2003). Simulation versus narrative. The video game theory reader. New York: Routledge. Food Force, (2011). http://www.wfp.org/videos/food-force-promo?page=31 Accessed June 2, 2017. Frontiers. (2015). https://www.frontiers-game.com/ Accessed May 18, 2017.

Games for Change. http://www.gamesforchange.org Accessed May 15, 2017.

Gee, J. P. (2010). Learning by design: Games as learning machines. Interactive Educational Multimedia, (8): 15-23.

Hattori, T. (2003). Giving as a mechanism of consent: International aid organisations and the ethical hegemony of capitalism. International Relations, 17(2): 153-173.

Höijer, B. (2004). The discourse of global compassion: The audience and media reporting of human suffering. Media, Culture \& Society, 26(4): 513-531.

Hutchison, E., Bleiker, R., and Campbell, D. (2014). Imaging Catastrophe: The Politics of Representing Humanitarian Crises. Negotiating Relief: the dialectics of humanitarian space.

Jensen, G. H. (2013). Making Sense of Play in Video Games: Ludus, Paidia, and Possibility Spaces. Journal for Computer Game Culture, 7(1): 69-80.

Johnson, H. L. (2011). Click to Donate: visual images, constructing victims and imagining the female refugee. Third World Quarterly, 32(6), 1015-1037.

Kirkpatrick, G. (2011). Aesthetic theory and the video game. Manchester: Manchester University Press.

Lewis, D., Rodgers, D., and Woolcock, M. (2014). Popular representations of development: Insights from novels, films, television and social media. London: Routledge.

Manzo, K., 2008. Imaging humanitarianism: NGO identity and the iconography of childhood. Antipode, 40(4), pp.632-657.

Michael, D. R., \& Chen, S. L. (2005). Serious games: Games that educate, train, and inform. Muska \& Lipman/Premier-Trade, Chicago.

My Life as a Refugee (2012). http://mylifeasarefugee.org Accessed May 24, 2017.

North (2016). https://outlands.itch.io/north Accessed May 18, 2017.

On the Ground Reporter: Darfur (2010). http://www.gamesforchange.org/play/on-the-ground-reporterdarfurl Accessed May 18, 2017.

Orgad, S. (2013). Visualisers of solidarity: organisational politics in humanitarian and international development NGOs. Visual Communication, 12(3): 295-314.

Papers, Please (2014). http://papersplea.se Accessed May 12, 2017.

Persuasive Games. http://persuasivegames.com Accessed May 22, 2017.

Raessens, J. F. F. (2015). Playful identity politics: How refugee games affect the player's identity.

Ratan, R., \& Ritterfeld, U. (2009). Classifying serious games. Serious games: Mechanisms and effects, 10-24.

Scott, M. (2014). Media and development. London: Zed books.

Serious Games Institute. http://www.seriousgamesinstitute.co.uk Accessed May 21, 2017.

Silverstone, R. (2006). Media and Morality: On the rise of the mediapolis. London: Polity,

Sigona, N. (2014). The politics of refugee voices: Representations, narratives, and memories. In: E. Fiddian-Qasmiyeh, ed., The Oxford Handbook of Refugee and Forced Migration, 1st ed. Oxford: Oxford University Press.

Smith, M. and H. Yanacopulos (2004). The public faces of development: An introduction. Journal of 
International Development, 16(5): 657-664.

The Independent (2015). Aylan Kurdi's story: How a small Syrian child came to be washed up on a beach in Turkey http://www.independent.co.uk/news/world/europe/aylan-kurdi-s-story-how-a-smallsyrian-child-came-to-be-washed-up-on-a-beach-in-turkey-10484588.html Accessed October 7, 2017.

The Migrant Trail (2014). http://www.gamesforchange.org/play/the-migrant-trail/ Accessed June 5, 2017.

UNESCO (2016). UNESCO takes World Humanitarian Summit into virtual journey with war reporters in Syria http://en.unesco.org/news/unesco-takes-world-humanitarian-summit-virtual-journey-war-reporterssyria Accessed June 12017.

Van Hear, N. (2014). Refugees, diasporas and transnationalism. The Oxford handbook of refugee and forced migration studies, 176.

White, A. (2015). Moving stories: International review of how media cover migration. Ethical Journalism Network. London.

Youtube (2016) Frontiers. https://www.youtube.com/watch?v=Yb3rfl2-hQQ Accessed October 2, 2017

Youtube (2015a). Against all Odds - Part 1 (War and Conflict) https://www.youtube.com/watch?v=OlJ1NpgybEU Accessed October 5, 2017

Youtube (2015b). Against all Odds - Part 4 ( A New Life). https://www.youtube.com/watch?v=LOz6tBx6N8Y Accessed October 5, 2017

Youtube (2015c) Cloud Chasers - A Journey of Hope (By Blindflug Studios) - iOS / Android - Gameplay Video https://www.youtube.com/watch?v=fVwTDvKd6To Accessed October 5, 2017

Zaytoun (2013). http://www.syriauntold.com/en/2013/06/video-game-zaytoun-the-young-syrianpalestinian-refugeel Accessed May 18, 2017.

\section{Notes}

${ }^{1}$ Arendt, The origins of totalitarianism. 88.

2 Boltanski, "Distant suffering."

${ }^{3}$ Scott, "Media and development."

${ }^{4}$ Smith and Yanacopulos, "Public faces of development". 658.

5 Johnson, "Click to Donate."

${ }^{6}$ Chouliaraki, The spectatorship of suffering. 89-90.

${ }^{7}$ Smith and Yanacopulos, "Public faces of development." 661.

${ }^{8}$ Ratan, R., \& Ritterfeld, Classifying serious games. Chapter 2.

${ }^{9}$ Bogost, "Persuasive Games."

10 Frontiers.

${ }^{11}$ Cloud chasers.

${ }^{12}$ Against all odds.

13 UNESCO, "World Humanitarian Summit."

${ }^{14}$ Lewis, Rodgers, and Woolcock, Popular representations of development.

15 Sigona, "Politics of refugee voices."

${ }^{16}$ Manzo, "Imaging humanitarianism." 649.

17 Johnson, "Click to Donate."

${ }^{18}$ The Independent, "Aylan Kurdi's story"

19 White, "Moving stories." 7

${ }^{20}$ Chouliaraki, The ironic spectator. Chapter 1.

21 ibid

${ }^{22}$ Höijer, "Discourse of global compassion." 516.

${ }^{23}$ Van Hear, "Refugees, diasporas and transnationalism."

${ }^{24}$ Chouliaraki, "The ironic spectator." Chapter 1.

${ }^{25}$ Hattori, "Giving as consent." 
${ }^{26}$ Scott, "Media and development." Chapter 5.

${ }^{27}$ Smith and Yanacopulos, "Public faces of development."

${ }^{28}$ Abt, "Serious games" Chapter 1.

${ }^{29}$ Abt, "Serious games" 9.

${ }^{30}$ Ratan and Ritterfeld, "Classifying serious games." 18.

${ }^{31}$ Connolly, Boyle, MacArthur, Hainey, and Boyle, "A systematic literature." 662.

32 Bogost, "Persuasive Games."

${ }^{33}$ Michael and Chen, "Serious games. 19.

${ }^{34}$ Ratan and Ritterfeld, "Classifying serious games." 14.

35 Serious Games Institute.

${ }^{36}$ Games for Change.

${ }^{37}$ Persuasive Games.

${ }_{38}$ Papers, Please.

${ }^{39}$ Against all odds.

${ }^{40}$ My Life as a Refugee.

${ }^{41}$ The Migrant Trail.

${ }_{42}$ Darfur is Dying.

${ }^{43}$ Cloud chasers.

44 North.

${ }^{45}$ Zaytoun.

${ }^{46}$ On the Ground Reporter.

${ }^{47}$ Food Force.

${ }^{48}$ Frontiers.

${ }^{49}$ Bogost, "The rhetoric of video games." 122-123.

50 Bogost, Persuasive Games. Chapter 1.

${ }^{51}$ Frasca, "Simulation versus narrative."

52 Bogost, Persuasive Games. Chapter 1.

53 Jensen, "Making Sense of Play."

${ }^{54}$ Bogost, "The rhetoric of video games." 123.

${ }^{55}$ Kirkpatrick, Aesthetic and video games. Chapter 1.

${ }^{56} \mathrm{lbid}$.

57 Youtube 2015a.

58 Youtube 2015b.

59 Youtube 2016.

60 Youtube 2015c.

61 Darfur is Dying.

62 Bogost, Persuasive Games.Chapter 1.

${ }^{63}$ Cloud Chasers.

${ }^{64}$ Against all odds.

${ }^{65}$ Belman, and Flanagan, "Designing games". 249.

${ }^{66}$ Chouliaraki, "The spectatorship of suffering."

${ }^{67}$ Silverstone, Media and Morality.

68 Bogost, Persuasive Games. Chapter 1.

${ }^{69}$ Lewis, Rodgers, and Woolcock, "Popular representations of development." Chapter 7.

${ }^{70}$ Chouliaraki, The spectatorship of suffering.

${ }^{71}$ Gee, "Learning by design."

72 Raessens, "Playful identity politics". 258.

${ }^{73}$ Dogra, Representations of global poverty

74 Hutchison, Bleiker, and Campbell, "Imaging Catastrophe."

${ }^{75}$ Belman, and Flanagan, "Designing games".

${ }^{76}$ Orgad, "Visualisers of solidarity."

77 Boltanski, "Distant suffering."

${ }^{78}$ Orgad, "Visualisers of solidarity."

79 Gee, "Learning by design." 
${ }^{80}$ Connolly, Boyle, MacArthur, Hainey, and Boyle, "A systematic literature." 662.

$81 \mathrm{lbid}$

82 Orgad, "Visualisers of solidarity."

${ }^{83}$ Connolly, Boyle, MacArthur, Hainey, and Boyle, "A systematic literature." 662.

84 UNESCO, "World Humanitarian Summit."

${ }^{85}$ Chouliaraki, "The ironic spectator."

URL: https://mc.manuscriptcentral.coin/ctwq E-mail: twq.admin@tandf.co.uk 